البصيرة: مجلة الدراسات الإسلامية

AL-BASHIRAH: JOURNAL OF ISLAMIC STUDIES

Vol. 2 No. 1 (2021): 49-65

Website: https://journal.stiba.ac.id

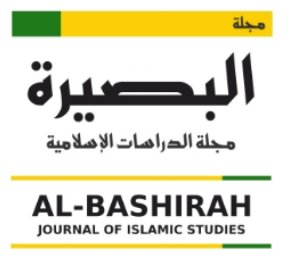

\title{
دراسة تحليلية عن كتاب النحو من سلسلة تعليم اللغة العربية في تعليم القواعد ومهارات اللغة العربية
}

\author{
رووين حممود الدين \\ المعهد العالي للدراسات الإسلامية والعربية بمكاسر \\ البريد الإلكتروين : ronny.mahmuddin@stiba.ac.id

\begin{abstract}
ز ت مولفيا سام
المعهد العالي للدراسات الإسلامية والعربية بمكاسر
\end{abstract} \\ البريد الإلكتروني : zulfiahsam@stiba.co.id
}

\section{المستخلص}

يستهدف هذا البحث إلى معرفة ووصف الكتاب المدرسي الجيد في تعليم مهارات اللغة العربية مع مراعاة تعليم القواعد النحوية، وأما نوع هذا البحث فهو البحث الوصفي الكيفي باستخدام الطريقة المكتبية بالدراسة التحليلية على كتاب مدرسي " كتاب النحو في سلسلة تعليم اللغة العربية" مع العثور على المصادر في جمع المعلمومات. ودلت نتائج هذا

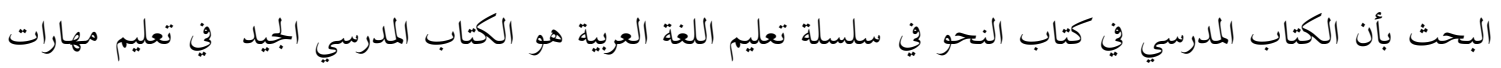

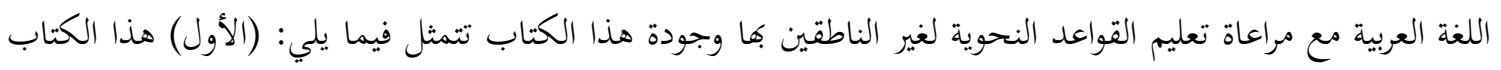
يستخدم طريقة المباشرة في تعليم مهارات اللغة العربية مع مراعاة تعليم القواعد النحوية، باستخدام اللغة العربية دون ترجمة

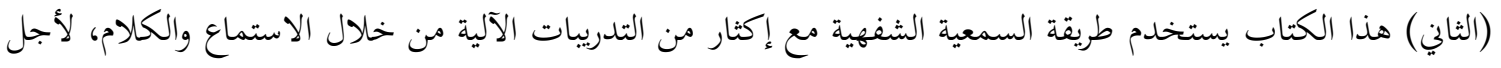
تكوين العادة لدى الدارسين مع تعلم القواعد النحوية من خلال السابق، (الثالث): هذا الكتاب يستخدم الطريقة الاستقرائية وهي الطريقة التي جعلت النص الحواري محورا لأنشطة اللغة كلاما أو قراءة تتعلق بالقواعد النحوية، مع استعمال

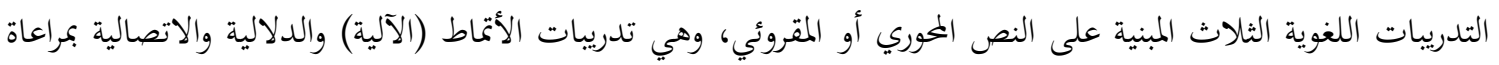
القواعد النحوية النظرية. و(الرابع) استخدم طريقة التواصلية في تعليم مهارات اللغة العربية مع مراعاة تعليم القواعد النحوية. الكلمات الدالة: الكتاب المدرسي، تعليم، مهارات، اللغة العربية، النحو. ورابع. 
Website: https://journal.stiba.ac.id

\title{
AN ANALYTICAL STUDY OF THE BOOK ON GRAMMAR IN THE ARABIC LANGUAGE TEACHING SERIES IN TEACHING GRAMMAR AND TEACHING ARABIC LANGUAGE SKILLS
}

\author{
Ronny Mahmuddin \\ Sekolah Tinggi Ilmu Islam dan Bahasa Arab (STIBA) Makassar \\ Email : ronny.mahmuddin@ stiba.ac.id \\ Zulfiah Sam \\ Sekolah Tinggi Ilmu Islam dan Bahasa Arab (STIBA) Makassar \\ Email : zulfiahsam@stiba.co.id
}

\begin{abstract}
This research aims to know and describe a good textbook in teaching Arabic language skills, taking into account the teaching of grammatical rules to non-native speakers. As for the type of this research, it is qualitative descriptive research using the office method by analytical study on a textbook "The Grammar Book in the Arabic Language Teaching Series" with finding On resources to collect information. The results of this research indicated that the textbook in the grammar book in the series of teaching the Arabic language is a good textbook for teaching Arabic language skills, taking into account the teaching of grammar rules to non-native speakers, and the quality of this book is as follows: (For the first) this book uses the direct method in teaching Arabic language skills, taking into account the teaching of grammar rules to non-native speakers, (second) this book uses the audio-verbal method with a multiplication of mechanical exercises through listening and speaking, in order to form the habit of students while learning the grammar rules Through Alsaqq, (the third): This book uses the inductive method, which is the method that made the dialogic text the focus of language activities in speech or reading related to grammatical rules, with the use of the three language exercises based on the axial or reciting text, which are the (mechanical), semantic and communicative exercises, taking into account Theoretical grammar and (Fourth) Use the communicative method in teaching Arabic language skills, taking into account the teaching of grammar.
\end{abstract}

Keywords: Textbook, education, skills, Arabic language, grammar.

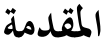

لا شك أن اللغة علامة ثقافة جميع الأمة وحضارتا، ولذلك الأمم كافة بلغاهما وتعمل على ترقيتها

وتقدمها.' وتعتبر اللغة من أهم المعايير التي تقاس بها فاعلية الأمم في مضمار التقدم والحضارة والتأثير والتأثر، ويقدر ما لمذه اللغة من أصالة وحيوية وانتشار وقدرة على مسايرة روح العصر والتعبير عما يجد فيه

$$
\text { ' محمود تيمور، مشكلات اللغة العربية، دون الطبعة (بيروت: منشورات المكتبة العصرية، دون سنة)، ص. ع. }
$$$$
50
$$ 
معان وعلوم ومصطلحات بقدر ما يكون لأصحاب هذه اللغة من مكانة عالية ودور عظيم في مضمار

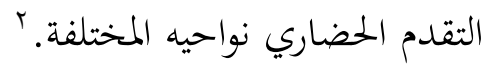

قد اختار الله اللغة العربية من سائر اللغات لحمل رسالة الإسلام على كافة الناس، وذكر في القرآن الكريم في عدة آيات على عربية القرآن، ومنها، قوله جل وعلى: $\}$

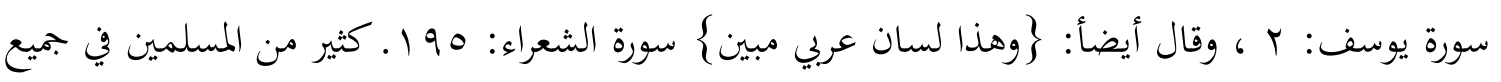

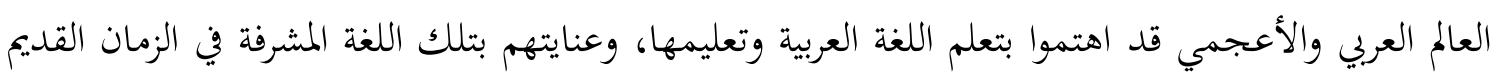

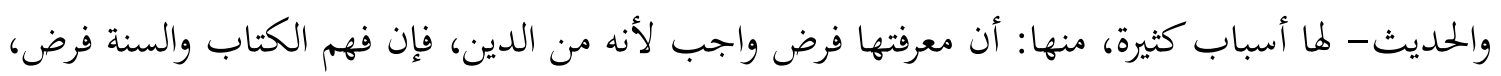
ولا يفهم إلا باللغة العربية.r إن علم النحو هو الذي له حق التقدم من العلوم العببية، إذ به يعرف صواب الكلام من خطئه

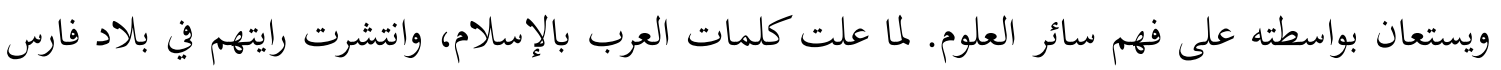

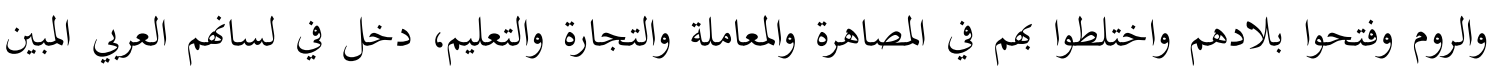

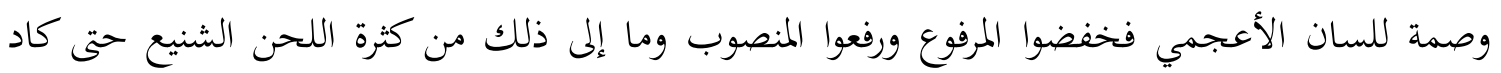

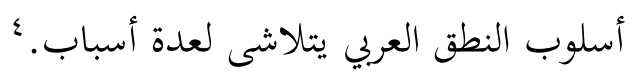
الابحاه المشهور في تدريس النحو سابقا أن تستغرق دروسه ساعات كثيرة، يقضيها المدرس في الشرح والتفصيل، بينما ينحصر درو الطلبة في مجرد الاستماع على طريقة القواعد والترجمة. وفي الخمسينيات

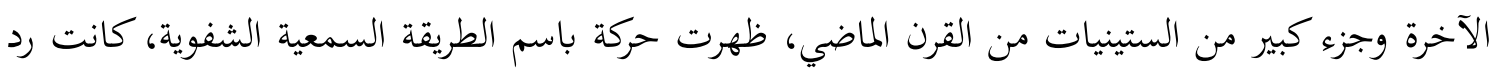

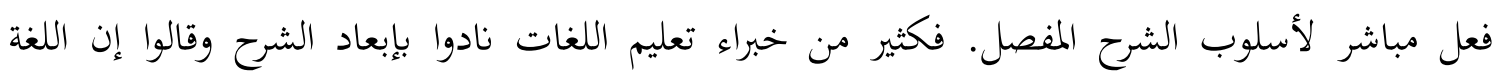

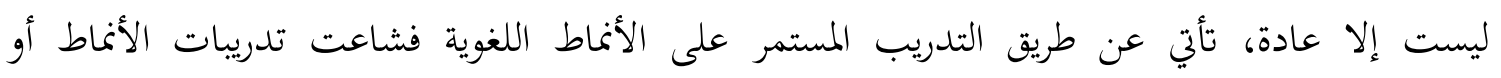

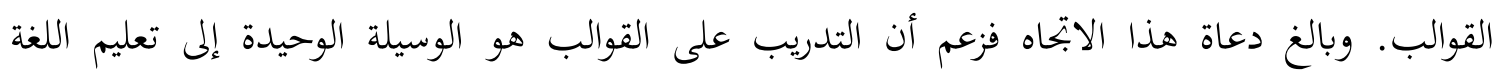

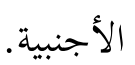

' r ممود كامل ناقة، تعليم اللغة العربية للناطقين بلغات أخري - أسسه ومداخله وطرق تدريسه-، دون الطبعة (المملكة

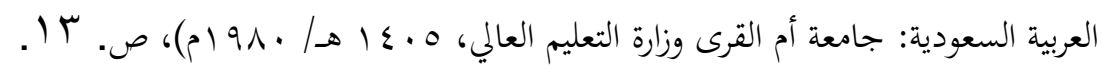

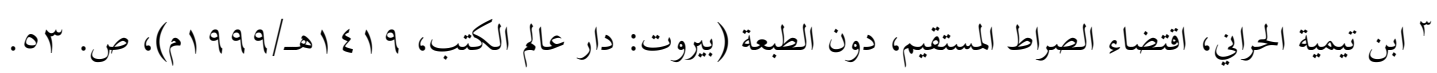

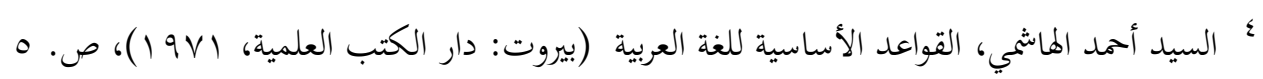


والإغراق في التدريبات الآلية ربما ساعد الدارسين على إجادة بعض الأنماط أو الصيغ النحوية،

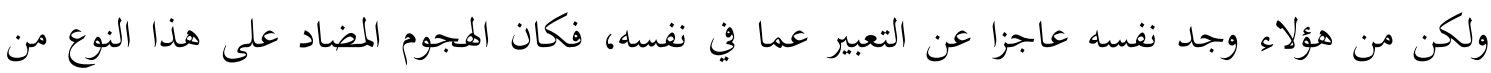

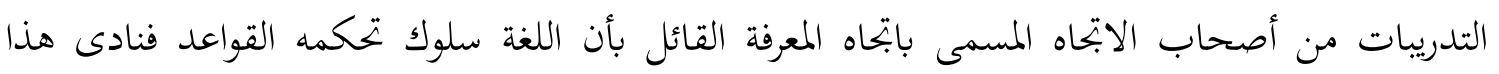

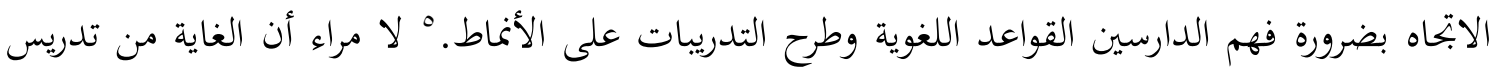

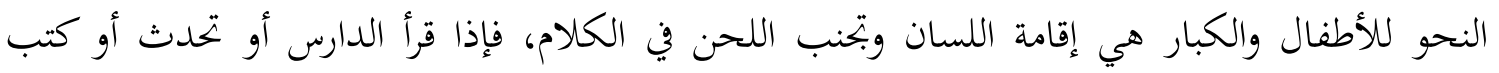
جاءت لغته سليمة وواضحة ومحققة للهدف منها. إن الغرض من تدريس النحو هو تكوين الملكة اللسانية

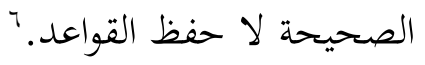

مما سبق بيانه، فلا بد من إيجاد كتاب مدرسي أو كتاب مقرر في الجمع بين الاتجاهين وهما الاتحاه

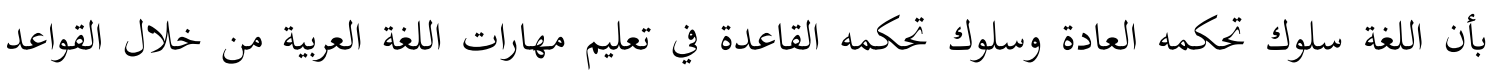

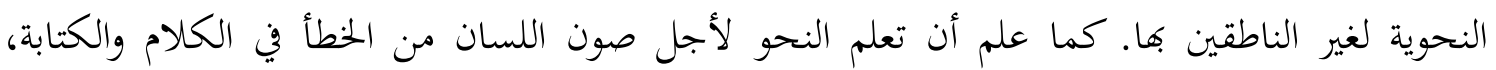
وكذلك لا يغفل على أهمية تطبيق الكلام بالطلاقة ومهارة الاستماع والكتابة مع مراعاة قواعد النحو.

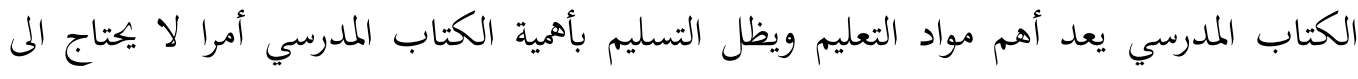
تقرير، فبرغم مما قيل ويقال عن تكنولوجيا التعليم وأدواته وآلاته الجديدة، يبقى للكتاب المدرسي مكانته المتردة في العملية التعليمية. هناك حاجة ماسة إلى إعداد مواد لتعليم اللغة العربية لغير الناطقين بها، حيث إن الموجود في الساحة من هذا النوع من المواد قليل جدا مقارنة بما هو موجود في اللغات التي اهتم اصحابها

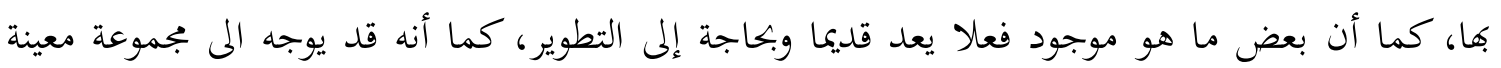
وبيئة معينة.

وذكر عمران حليم من أزهر أرشد أنه بناءً على نتائج الدراسة ، فإن عامل الفشل في تعلم اللغة

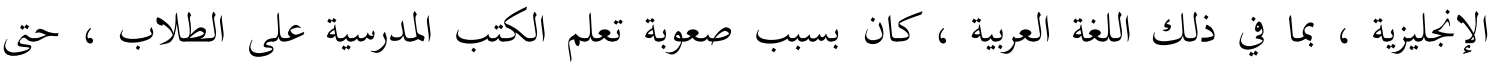
المعلمين واجهوا صعوبة في تدريسها. تم إجراء بحث يتعلق بفاعلية استخدام الكتب المدرسية باللغة الإنجليزية

هعبد الرمن بن إبراهيم الفوزان ، إضاءات لمعلمي اللغة العربية لغير الناطقين بها، الطبعة الأولى (الرياض: مكتبة الملك فهد

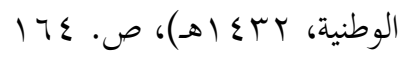

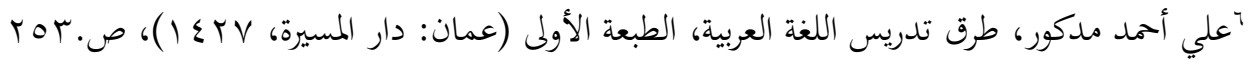

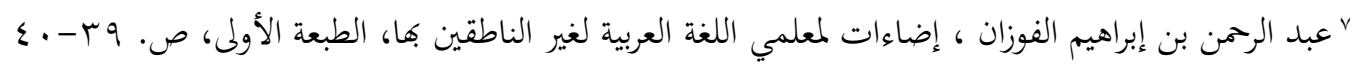


في المدارس الإعدادية والثانوية ، لذلك أظهرت نتائج الباحثين أن حوالي ه\% فقط من معلمي المدارس

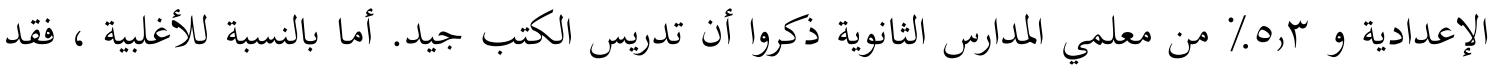

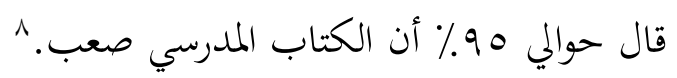

وعزز منير التصريح أعلاه قائلاً إن تعلم اللغة العربية في المدارس الدينية تحت إشراف وزارة الدين بدا أقل وضوحًا ومسؤولية. هذا الافتراض لأن الطلاب لا يستطيعون إتقان مهارات التحدث أو أت إتقان

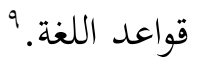

أظهرت تيكا مرضية في دراسة أن إحدى مدارس الثانوية في مدرسة بيسانترين بجاوة ، والتي تمثل مشكلة في تدريس اللغة العربية ، تتعلق بمواد تعليمية ليست ذات صلة بأهداف مراف التعلم ، وتنفيذ المناهج

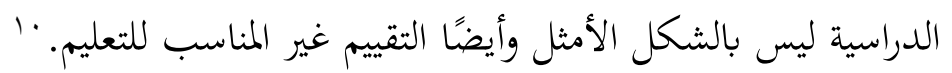

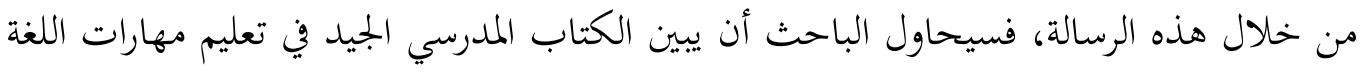
مع الاهتمام بالقواعد النحوية لغير الناطقين بها جمعا بين الاتحاهين. وهو كتاب النحو من سلسلة تعليم

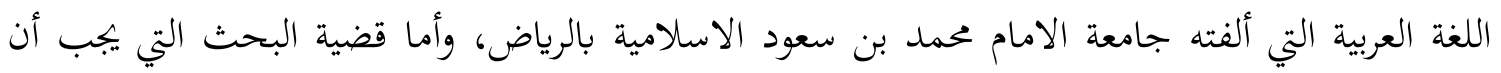
تعالج وتحلل في هذا البحث ، فهي ما مدى مزايا كتاب النحو في سلسلة تعليم اللغة العربية في تعليم

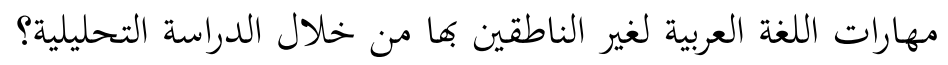
وهذا البحث يستهدف إلى معرفة ووصف الكتاب المدرسي الجيد في تعليم مهارات اللغة العربية

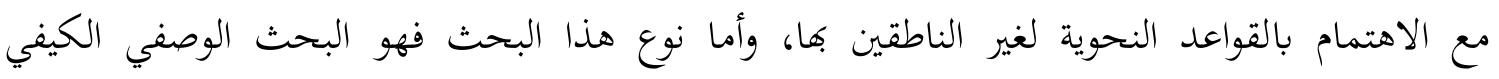

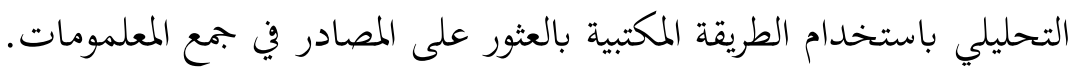

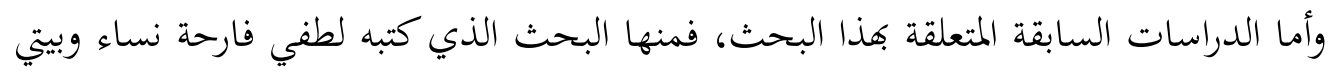
Kitab Turats Sebagai Solusi Efektifitas Pembelajaran " استيف فني واريا وحي فارتمة بعنوان ،" Mata Kuliah Tarkib Ibtida’i Di Jurusan Sastra Arab Universitas Negeri Malang

Azhar Arsyad, Bahasa Arab dan Metode Pengajarannya, (Cet. II; Jogjakarta: Pustaka Pelajar, 2004), h.

Munir, Perencanaan Sistem Pengajaran Bahasa Arab (Cet. I; Jakarta: Kencana; 2017), h. $38 .{ }^{\circ}$ Tika Mardiyah, Problematika Pengajaran Bahasa Arab Di Madrasah Tsanawiyah Pesantren Sabilil '. Muttaqin Tulungagung. Jurnal Prespektive, Vol.X, No. 02 (2017), h: 20-43. 


$$
\begin{aligned}
& \text { والهدف من البحث هو وصف طرائق تدريس النحو باستعمال كتب التراث، وأما نتائج البحث فهي أن } \\
& \text { طريقة مثلى في تدريس النحو هي باستعمال كتب التراث." } \\
& \text { وكذلك البحث الذي له علاقة هذذا البحث هو البحث الذي كتبه محمد زينوري بعنوان: }
\end{aligned}
$$

Analisis Buku Ajar Belajar Membaca Kitab Kuning Metode Ibtida'i Karya Mujahidin

Rohman

واستهدف هذا البحث إلى وصف طريقة تدريس كيفية قراءة الكتب العربية بدون الشكل ،

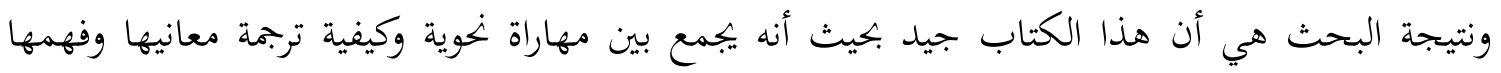

وأيضا البحث الذي كتبته ريني ديوي سوسانتي بعنوان "Studi Analisis Buku Ajar "Buku

Teks Pelajaran" Pada mata Pelajaran Bahasa Arab di kelas Tinggi Madrasah الح

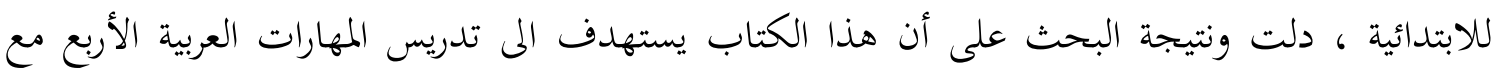
استخدام طريقة القياسية.

حسب التطلع على الرسائل والدراسات العلمية لم يجد الباحث من قام بالبحث في مثل هذا

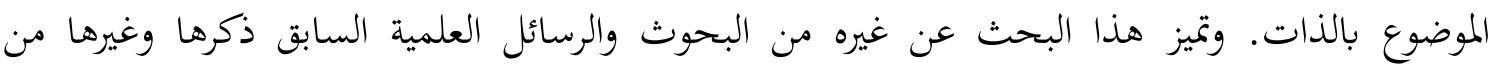

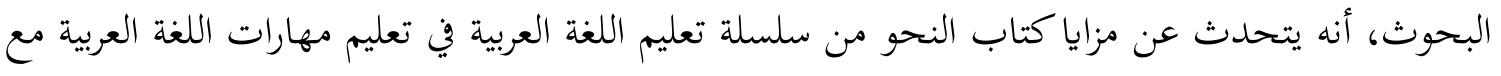

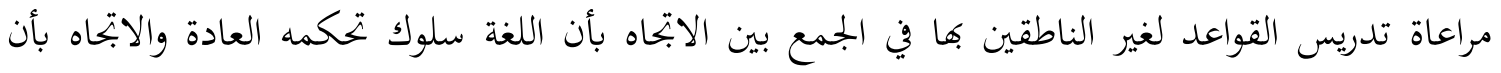
اللغة سلوك تحكمه القاعدة من خلال الدراسة التحليلية.

Luthfi Farihatun Nisa, Bety Istif Fani dan Arya Wahyu Pratama, Kitab Turats Sebagai Solusi Efektifitas Pembelajaran Mata Kuliah Tarkib Ibtida'i di Jurusan Sastra Arab Universitas Negeri Malang. Vol. 4 (2020). http://prosiding.arab-um.com/index.php/semnasbama/article/view/618. Analisis Buku Ajar Belajar Membaca Kitab Kuning Metode Ibtida'i Karya Mujahidin Rohman ${ }^{\text {ir }}$ Jurnal Arabia, Vol. 11, No. 1, 2019, h. 191-212. https://journal.iainkudus.ac.id/index.php/Arabia/article/view/5255

${ }^{13}$ Reni Dwi Susani, Studi Analisis Buku Ajar "Buku Teks Pelajaran” Pada mata Pelajaran Bahasa Arab di Kelas Tinggi Madrasah Ibtidaiah, Jurnal Arabi., Vol. 5 No. 2 (April- Desember 2013), h. 199-223. https://journal.iainkudus.ac.id/index.php/Arabia/article/view/1389. 
البصيرة: مجلة الار اسـات الإسلامية

AL-BASHIRAH: JOURNAL OF ISLAMIC STUDIES

Vol. 2 No. 1 (2021): 49-65

Website: https://journal.stiba.ac.id

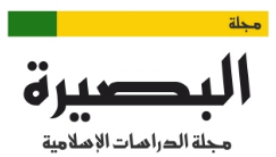

AL-BASHIRAH

بعدما قام الباحث بدراسة تحيلية عن كتاب النحو من سلسلة تعليم اللغة العربية التي ألفتها جامعة الإمام محمد بن سعود الاسلامية بالرياض في تعليم القواعد النحوية ومهارات اللغة العبية، فتميز هاذا الكتاب محا يلي:

\section{الأول: استخدام طريقة المباشرة في تعليم القواعد النحوية ومهارات اللغة العربية}

تمتاز طريقة المباشرة بما يلي: الاهتمام بمهارة الكلام وعدم اللجوء إلى الترجمة عند تعلم اللغة الأجنية، وعدم تزويد الطلبة بقواعد اللغة النظرية والاكتفاء بتدريبه على قوالب اللغة وتراكيبها والربط بين

الكلمة والشي الذي تدل عليه واستخدام أسلوب المحاكاة والحفظ. \&1

بناء على هذا، فكتاب النحو من السلسلة يعد مستخدما طريقة المباشرة في التعليم لأنه: 1- هذا الكتاب استخدم اللغة العربية عرض المادة أو الموضوع وعرض التدريبات.

r- من إرشادات للمعلم هو أن المعلم لفذا الكتاب لا بد من استخدام اللغة العربية في التدريس.

r- تعليم المفردات من خلال سياق الجملة ليس بجرد تلقينها. ع - تعليم القواعد النحوية من خلال التطبيق (الكلام) بكثرة التدريبات. ه- - معليم مهارات اللغة العربية الأربع باستخدام اللغة العربية مباشرة دون

$$
\text { ترجمة. }
$$$$
\text { \& أعبد الرحمن بن إبراهيم الفوزان، إضاءات لمعلمي اللغة العربية لغير الناطقين بها، ص.V9 }
$$ 
البصيرة: مجلة الار اسـات الإسلامية

AL-BASHIRAH: JOURNAL OF ISLAMIC STUDIES

Vol. 2 No. 1 (2021): 49-65

Website: https://journal.stiba.ac.id

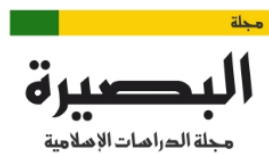

مجلة الدراهات الإهلامية

AL-BASHIRAH

الثاني: استخدام طريقة السمعية الشفهية في تعليم القواعد النحوية ومهارات اللغة العربية من أهم أسس هذه الطريقة (الطريقة السمعية الشفهية)، هي استعمال الوسائل السمعية والبصرية

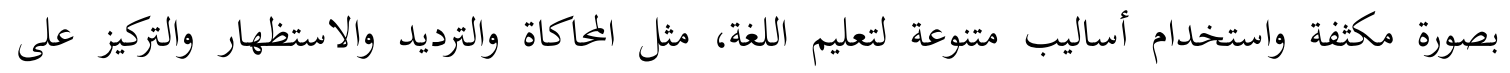

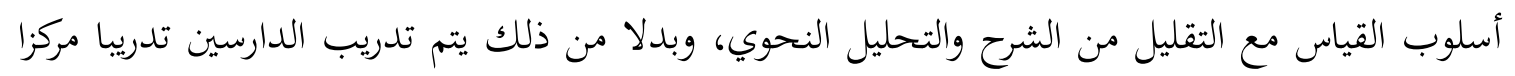

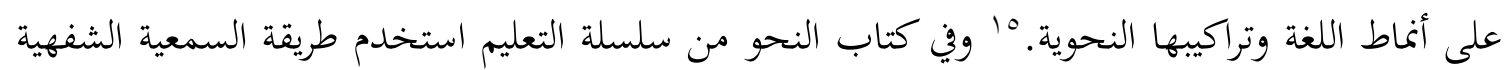

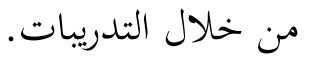

من أهم الأهداف في تعليم القواعد النحوية في المرحلة الابتدائية هي أن يتعرف الدارس على نسق

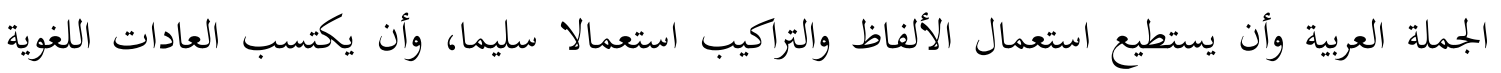

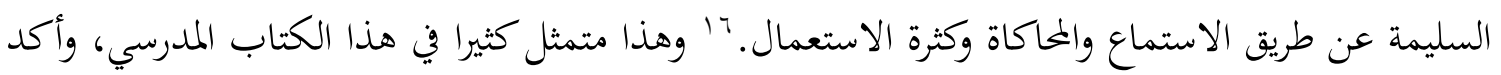
كذلك عبد العليم إبراهيم الغرض من تعليم القواعد أها وسيلة لضبط الكلام وصحة النطق والكتابة، وليست غاية مقصودة لذاتا, وقد أخطأ كثير من المعلمين حين غالوا بالقواعد، واهتموا بجمع شواهدها

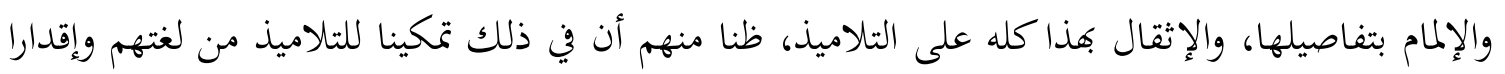
لهم على إجادة التعبير والبيان. V' وهذا الكلام منطبق في هذا الكتاب المدرسي بحيث أنه يهتم كثيرا بالتدريبات التي تعود الطلبة في الكلام مع مراعاة القواعد، وذكر محمود الناقة أن تعلم اللغة عن طريق هليق

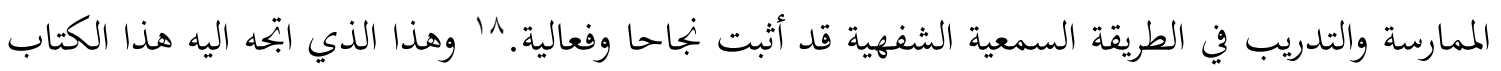

$$
\text { المدرسي حيث إنه يوفر كثيرا من التدريبات السمعية والشفهية. }
$$

بناء على هذا، أن الكتاب المدرسي هو كتاب حيد في تعليم القواعد النحوية للدارسين المبتدئين

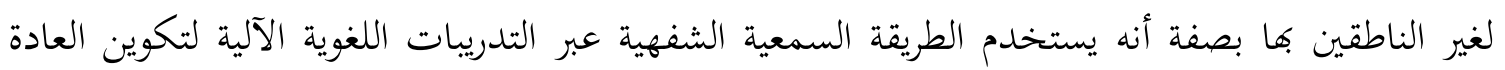

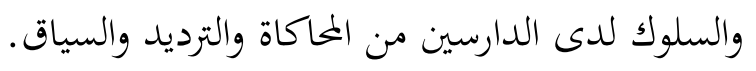

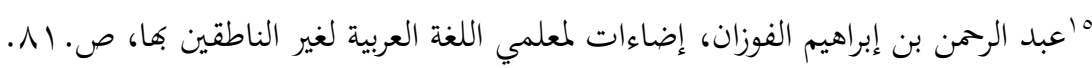

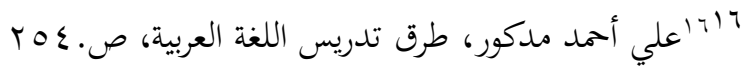

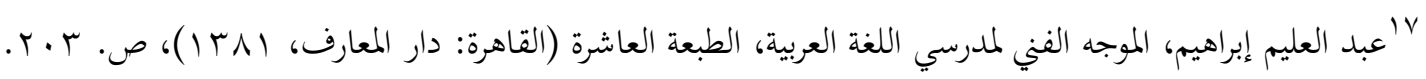

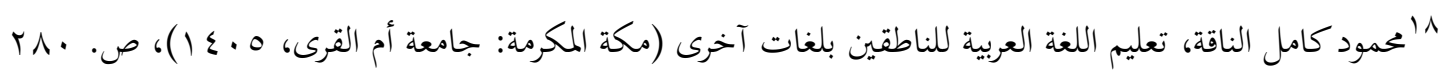




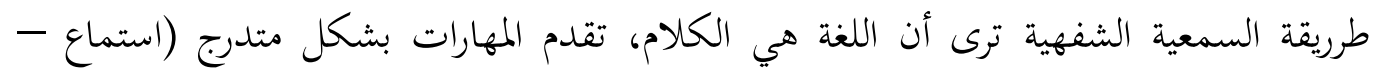
تحدث - قراءة - كتابة)، تركز على تطلق الأصوات، تقدم النصوص على شكل حوارات، نعلم المفردات

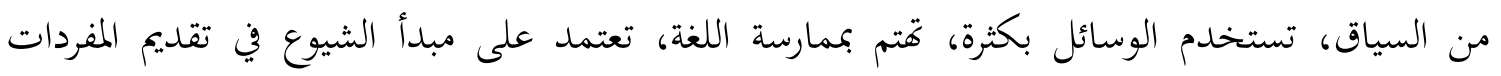
والتراكيب، وتتم بالصحة اللغوية والنطق الصحيح للأصوات. 19

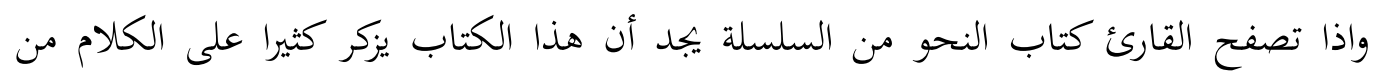

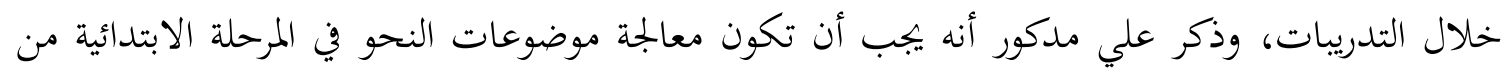

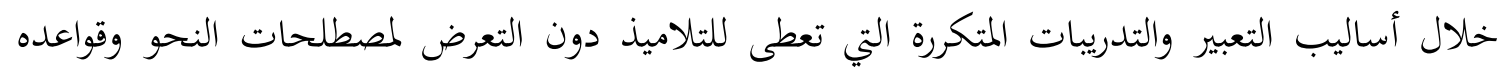

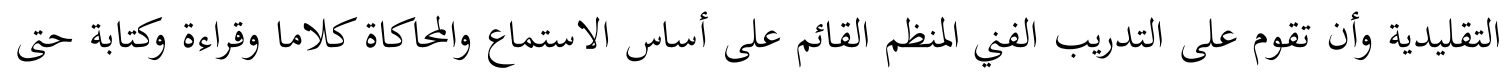

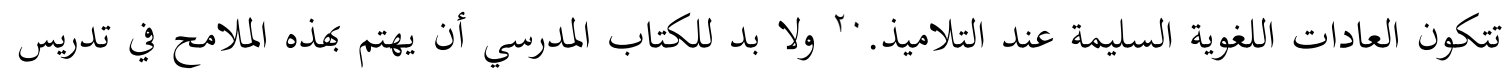

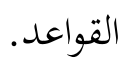

$$
\text { من المبادىء التي يقوم عليها اختيار التراكيب أو القواعد النحوية وهي: }
$$

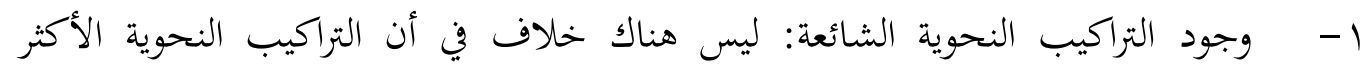

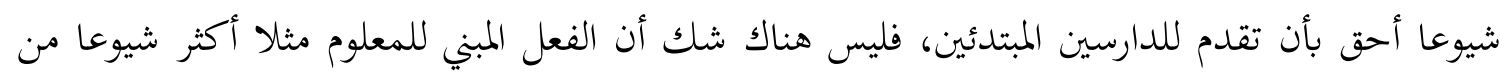
الفعل المبني للمجهول، والمفرد أكثر شيوعا من المثنى.

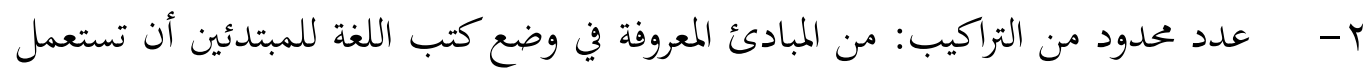

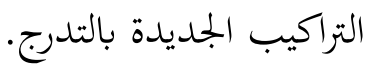

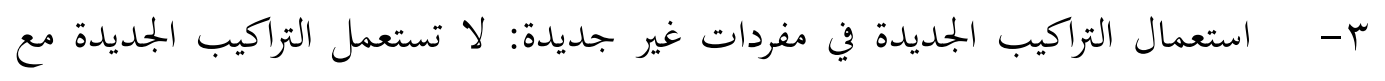
مفردات جديدة إلا في الدرس الأول. ع - التكرار: من الضروري أن تتكرر التراكيب اللغوية عددا كافيا من المرات.

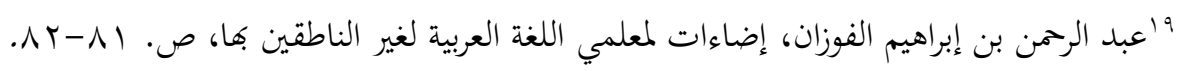

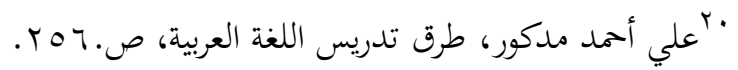


هـ - مواة التركيب قبل التركيب الموسع:لا يصح إدخال تركيب في صورة من صوره الموسعة قبل

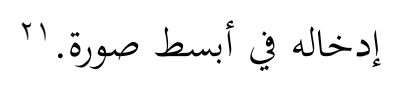

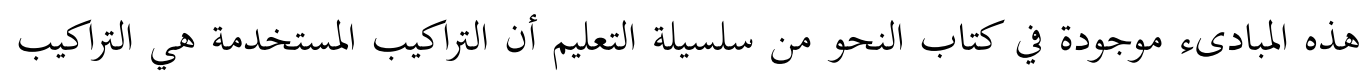

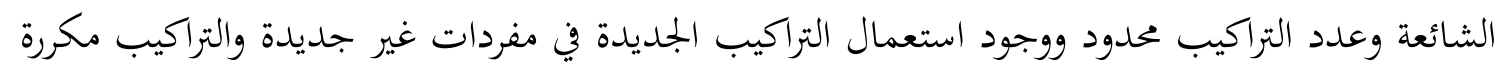
و بدء من التركيب البسيط إلى التركيب الموسع.

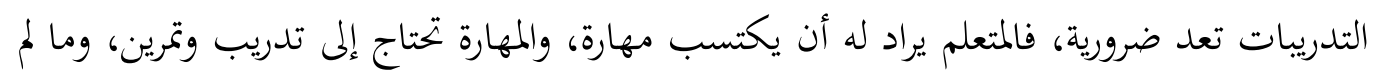

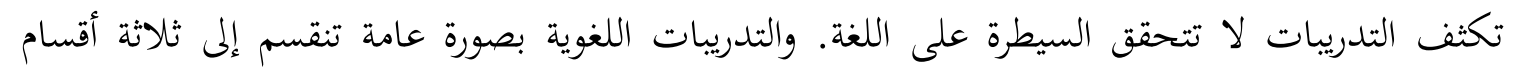

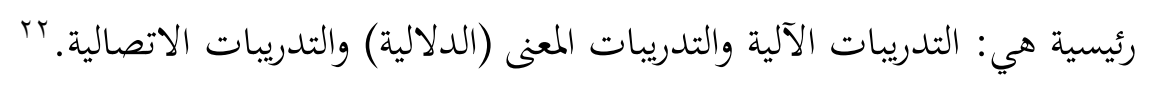

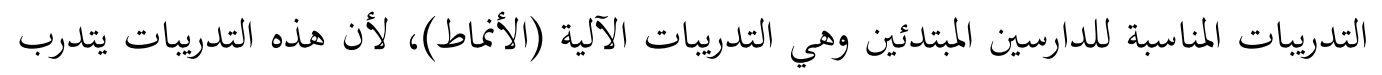

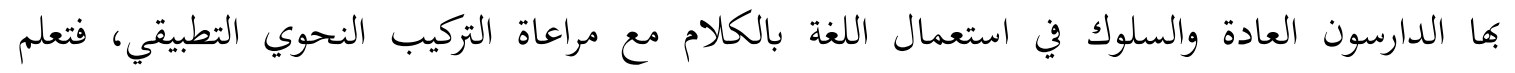

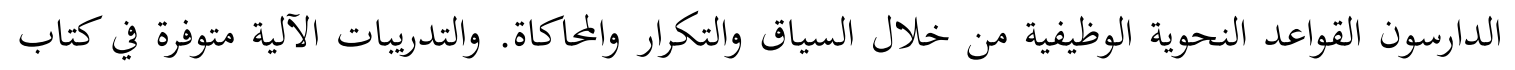
النحو من سلسلة التعليه. التدريات الآلية هي التدريات التي يتم فيها التحكم التام في استجابة الدارس، بحيث تكون هناك اكت التاك

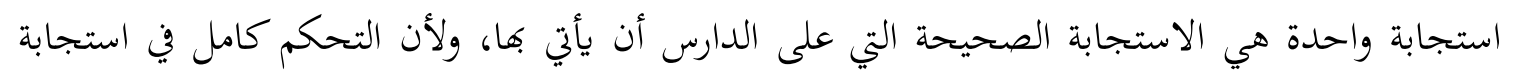

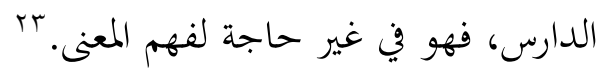
ذكر في كتاب النحو من سلسلة التعليم نماذج التدرييات الآلية ومنها تدرييات الاستبدال. تدرييات الاستبدال تعتبر نموذجا لهذا النشاط الآلي، حيث يقوم الدارس في هذا النوع من التدرييات بإجراء

1ابانظر: داود عبده، التزاكيب اللغوية في كتب تعليم العربية لغير الناطقين بها (السودان: الجلة العربية للدراسات اللغوية،

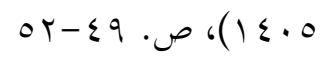
rr

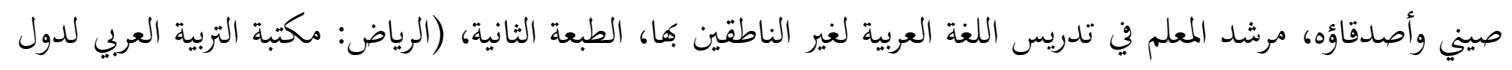

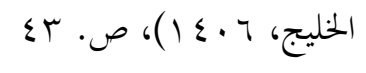

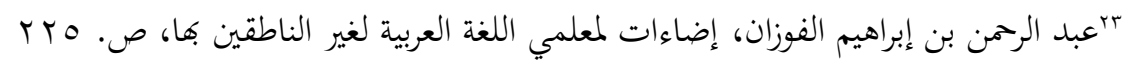


بعض التغييرات في البنية بناء على المثيرات التيى يتلقاها من المدرس. ويوضح المثال التالي، هذه الآلية التي

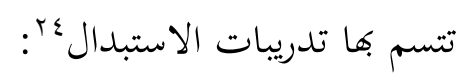

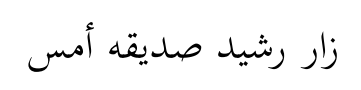

\begin{tabular}{|c|c|}
\hline (يصافح) & \\
\hline (والد) & ९.............. \\
\hline (يستقبل) & $\stackrel{\wp}{\varrho}$ \\
\hline
\end{tabular}

$$
\text { قابل رشيد صديقه أمس صدس }
$$

وتعتبر تدريات التحويل نموذجا لهذا النشاط الآلي كما يتضح من المثال التالي:

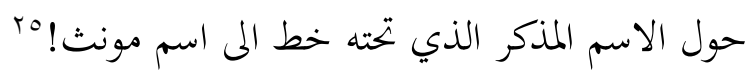

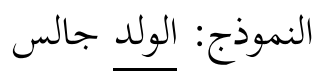

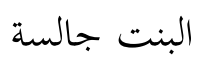

$$
\begin{aligned}
& \text { 1- الأب رحيم: :................ } \\
& \text { r............... }
\end{aligned}
$$

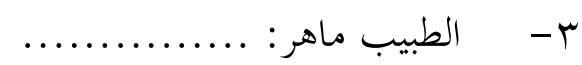

إن الهدف النهائي المتوقع من التدريبات الآلية هي سيطرة الدارس على النمط بشكل تلقائي،

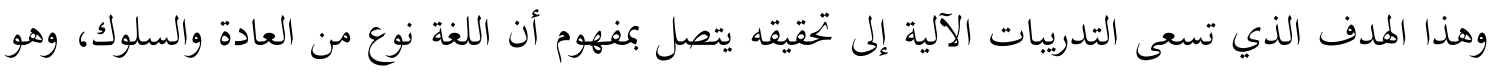

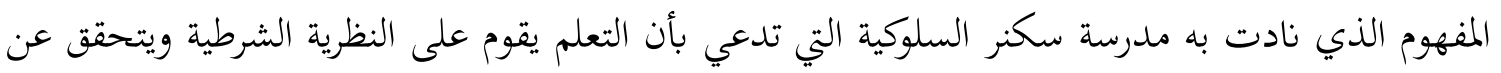

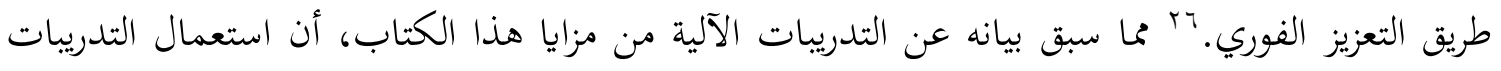

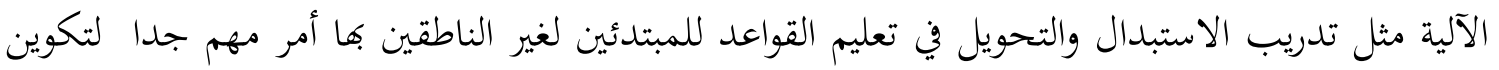
العادة في مهارات الكلام لدى الطلبة.

گَ عبد الله ين حامد الحامد، كتاب النحو من سلسلة تعليم اللغة العربية للمستوى الثاني، الطبعة الثانية (الرياض: جامعة

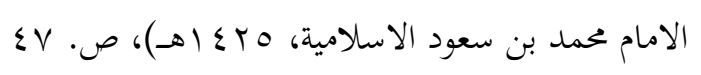

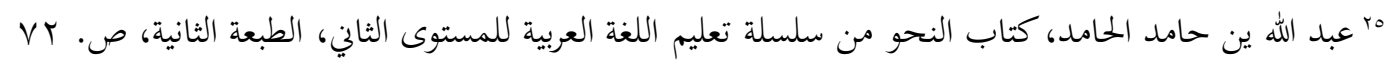

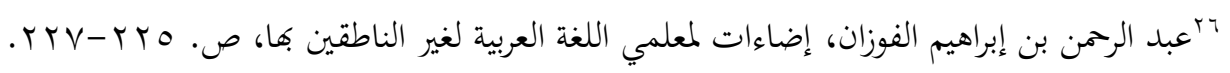


البصيرة: مجلة الار اسـات الإسلامية

AL-BASHIRAH: JOURNAL OF ISLAMIC STUDIES

Vol. 2 No. 1 (2021): 49-65

Website: https://journal.stiba.ac.id

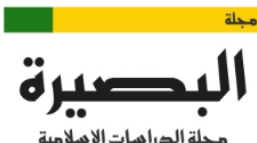

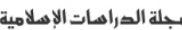

AL-BASHIRAH

\section{الثالث: استخدام الطريقة الاستقرائية في تعليم القواعد النحوية ومهارات اللغة العربية}

ذكر محمود علي السمان أن قواعد اللغة من علوم العربية التي يقصد بتعليمها كسب المعرفة فإن الطريقة الاستقرائية هي أقرب الطرق ملائمة لتدريسها، إذ السير فيها يكون من الأمثلة إلى القاعدة. rV كثيرا ما وجد في ساحة تعليم القوعد النحوية أن تعليم القواعد النحوية مجرد حفظ القواعد والتعريفات والمصطلاحات مع إغفال جانب مهارة الكلام والاستماع مع أن اللغة هي الكلام أو استعمال اللغة وتكوين السلوك والعادة، فذكر عبد الرحمن الفوزان مراحل تعليم القواعد النحوية للمتقدمين لغير الناطقين بها^r، ومن أمثلة تدريس القواعد على الطريقة الاستقرائية كما ذكر في كتاب النحو من سلسلة تعليم اللغة العربية التي أصدرته جامعة الإمام محمد بن سعود بالرياض وهي فيما يلي: المثال: النص: البطتان والسلحفاة

النهر صغير والسلحفاة واقفة أمام النهر تنظر إليه ماء النهر قليل وقد جف جزء كبير من النهر. فنظرت السلحفاة إلى الشجرة التي بجوار النهر فرأت بطتين فوق الشجرة قالت لمما: ماذا ستفعلان بعد جف ماء النهر؟..... أسئلة الاستيعاب:

\section{- - - - كيف حملت البطتان السلحفاة؟

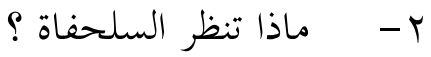

ثم بعد هذا، يشرح المعلم القواعد التي سيدرسها الدارسون مع الربط والموازنة بين الأمثلة المأخوذة من النص ثم استخراج القاعدة، ثم بعد ذلك ينتقلون إلى حل التدريبات اللغوية الثلاثة وهي التدريبات الآلية والتدريبات الدلالية والتدريبات الاتصالية. ·r

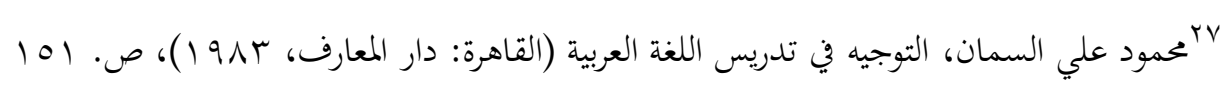

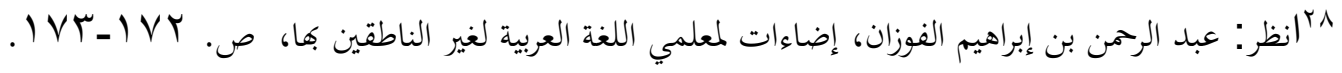

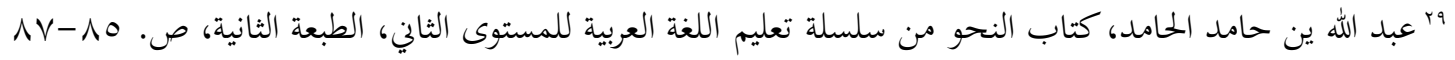

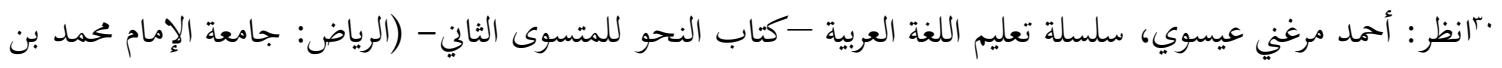

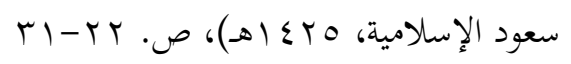


رأى الباحث أن هذه الطريقة (الطريقة الاستقرائية) مناسبة للدارسين المتقدمين لأغم جمعوا بين

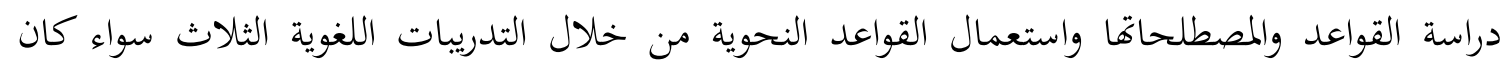
بالكلام أو الكتابة.

على الكتاب المدرسي الجيد مراعاة مراحل طريقة تدريس القواعد النحوية الاستقرائية، كما ذكرها الفوزان في تعليم القواعد النحوية للمتقدمين، فهذه هي المراحل التالية:

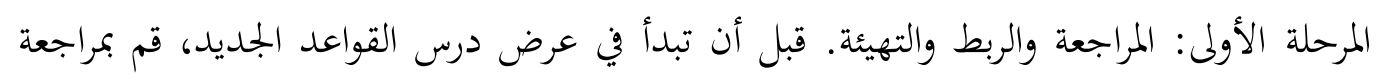
دروس القواعد السابقة. المرحلة الثانية: المناقشة. اختبر بعض الدارسين لقراءة الأمثلة ثم قم بمناقشة الأمثلة لتتأكد أفم فهموا معانيها، وشجع الدارسين على استنباط قواعد الدرس عن طريق الحوار والأسئلة. المرحلة الثالثة: الشرح. قم بشرح الدرس بطريقة واضحة وشجع الدارسين على طرح أسئلتهم.

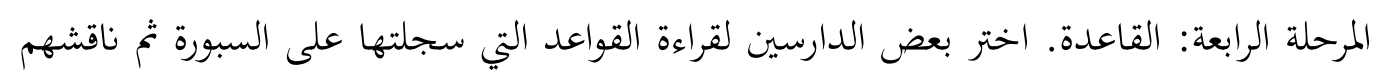
فيها عن طريق الأسئلة.

المرحلة الخامسة: التدريبات. انتقل إلى مرحلة التدريبات متبعا الأساليب المختلفة لإجرائها.'” ذكر محمود كامل الناقة أن تدريس قواعد اللغة للمتعلم يمكن يحقق هدفين هما: الهدف الأول: أن تدريس القواعد للمبتدئين ينبغي أن يوجد إحساسا لغويا صادقا وطليقا لدى المتعلم. الهدف الثاني: أما في المستويات المتقدمة وعندما تمت السيطرة على اللغة إجرائيا ينبغي أن تصبح

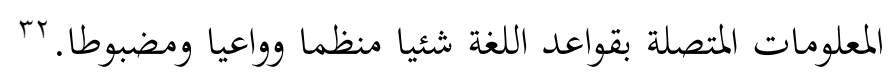
هناك ثلاث التدريبات اللغوية في تعليم القواعد النحوية للمتقدمين لغير الناطقين بها، وهي واتيات التدريبات الآلية والتدريبات الدلالية والتدريبات الاتصالية.

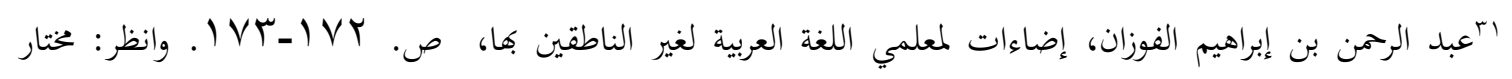

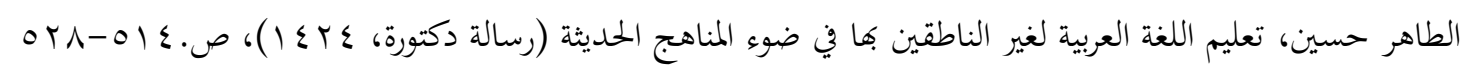

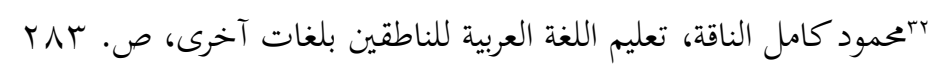


أما نماذج التدريبات الآلية فقد ذكرها الباحث في المبحث عن طريقة تدريس القواعد النحوية للمبتدئين. فالتدريبات الآلية مهم أيضا للمتقدمين لأجل تكوين العادة لدى الدارسين، ولكن لا لا تعطى هذه التدريبات بكثرة لأفم قد مروا بهذه التدريبات في المرحلة الابتدائية.

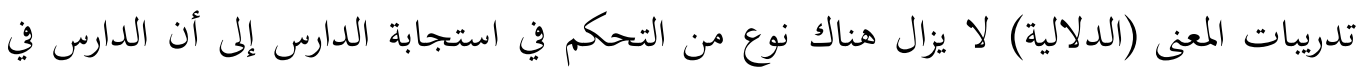
هذه التدريبات يمكنه التعبير عن المعنى بأكثر من طريقة وهي في هذا تختلف عن التدريبات الآلية التي تخلو

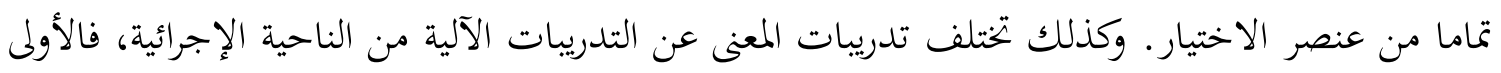

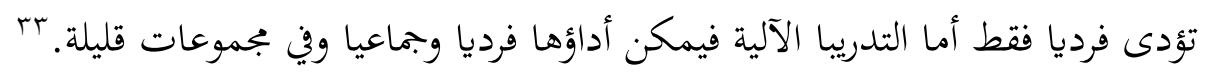

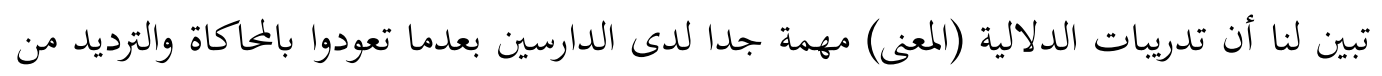

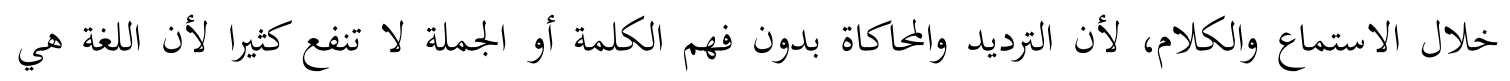
تطبيق الكلام مع فهم ما يتكلم عنه. وأفضل مثال لتدريبات المعنى، تدريبات السؤال والجواب التي تستخدم عادة في التدريب على فهم

$$
\text { المقروء وفهم المسموع. والمثال التالي يوضح هذا النوع من التدريبات: }
$$

نص: (( حضر السيد فريد من السودان إلى القاهرة، درس اللغة العربية في جامعة القاهرة، وبعد

$$
\begin{aligned}
& \text { الدراسة رجع إلى السودان، وهو الآن موظف كبير في الخرطوم)) } \\
& \text { أسئلة: } \\
& \text { - - - من أين السيد فريد؟ } \\
& \text { r - r أين يدرس؟ } \\
& \text { r- ب - هل حصل على شهادة جامعية؟ } \\
& \text { ع - هل هو طالب الآن؟ }
\end{aligned}
$$

\section{الرابع: استخدام طريقة التواصلية الاتصالية في تعليم القواعد النحوية ومهارات اللغة العربية}

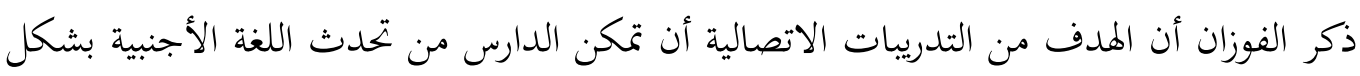

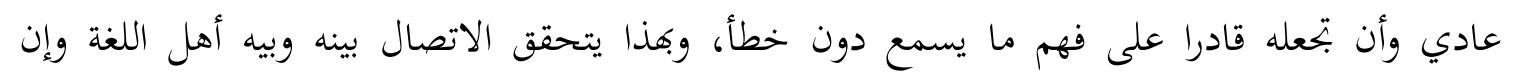

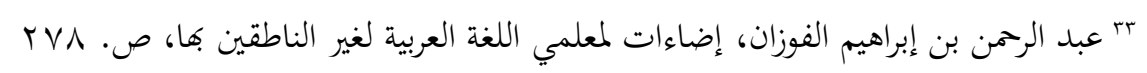


الدارس حر في أن يقول ما يشاء كيفما يشاء. يتمثل في أن الدارس يأتي في التدريبات الاتصالية بمعلومات

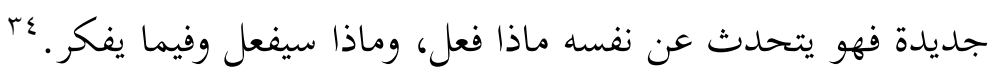

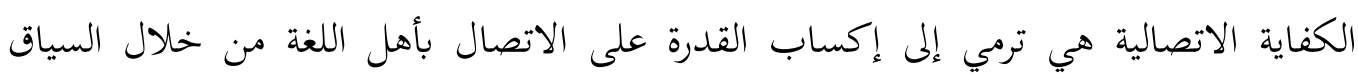

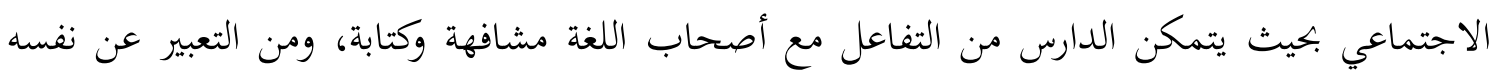

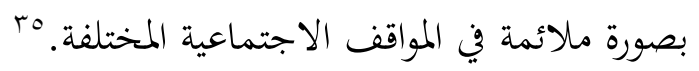
الدارس في التدرييات الاتصالية يأتي بمعلومات جديدة لا يعرفها أحد من الميطين به كما يتضح من المثال التالي في كتاب النحو من السلسلة:

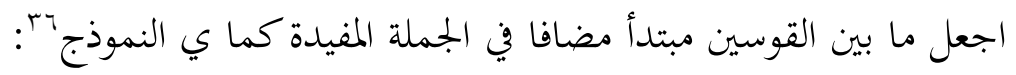

$$
\text { النموذج: (طريق): طريق المطار واسع العين }
$$

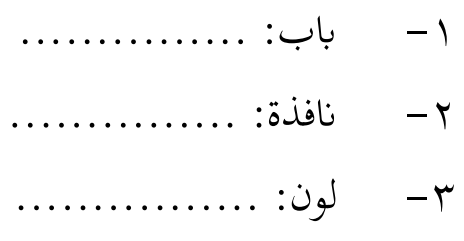

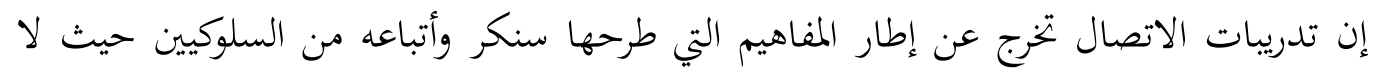

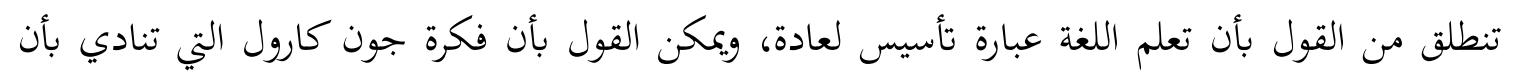

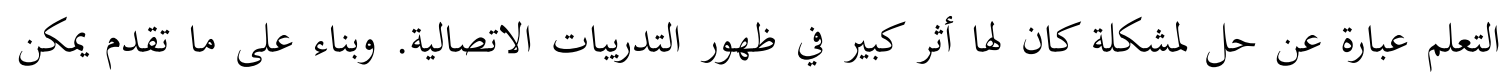

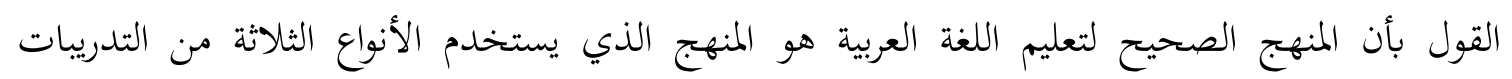
السابقة في تكامل وتوازن.

بناء مما سبق بيانه تبين أن هذا الكتاب اهتم كثيرا بطريقة الاتصالية التواصلية من خلال التدريبات ،ولذا فلا بد من استعمال هذه الطريقة في تعليم القواعد النحوية ومهارات اللغة العربية، إذ أن تعليم

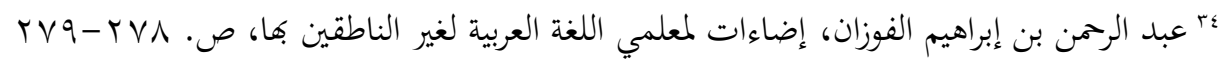

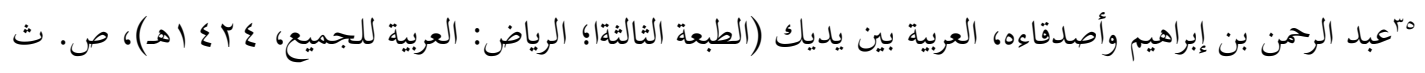

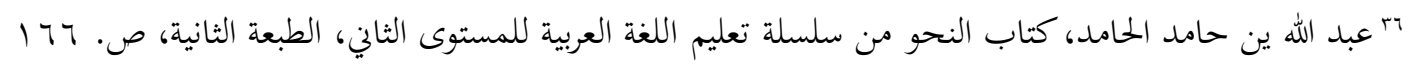
TrV 
القواعد بدون استعمال هذه القواعد في الكلام لا ينفع كثيرا، لأن الهدف من تعليم القواعد هو صون اللسان من الخطأ في الكلام، وليس مجرد حفظ القواعد ومصطلحاها.

ختام هذا البحث، فذكر الباحث بعض التلخيصات حول الموضوع أن كتاب النحو من السلسلة تميز بميزات:

الأول: استخدام طريقة المباشرة في تعليم القواعد النحوية ومهارات اللغة العربية، باستخدام اللغة

$$
\text { العربية دون ترجمة. }
$$

الثاني: استخدام طريقة السمعية الشفهية في تعليم القواعد النحوية ومهارات اللغة العربية. هذا

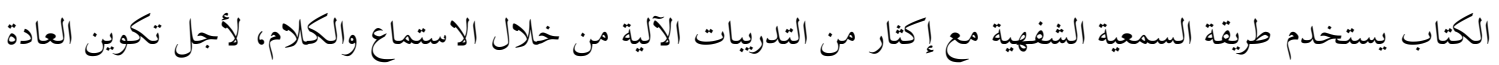

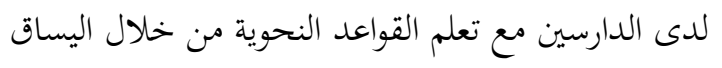

الثالث: استخدام طريقة الاستقرائية في تعليم القواعد النحوية ومهارات اللغة العربية. وهي الطريقة

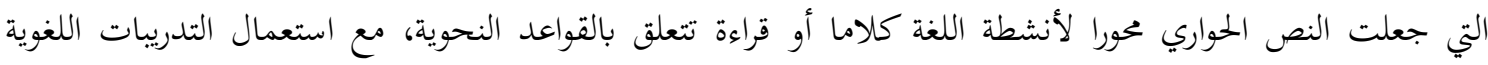

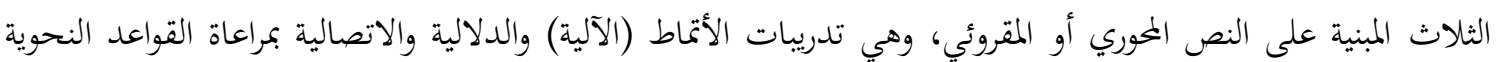

النظرية.

الرابع: استخدام طريقة التواصلية الاتصالية في تعليم القواعد النحوية ومهارات اللغة العربية، من

خلال التدريبات التواصلية.

\section{فهرس المصادر بالعربية}

'Abduh, Dāwūd. Al-Tarākīb al-Lugawīah fì kutub ta 'lìm al- 'Arabīah ligaīri al-Nātiqīna biha. Al-Sūdān: al-Majallah al-'Arabīah lī al-Dirāsāt al-Lugawīah, 1985

Al-Fauzān, 'Abd al-Raḥmān bin Ibrāhīm. Idẹa'āt lì mu'allimī al-Lugah al- 'Arabīah ligairi al-Nätiqiña biha. Al-Ṭab'ah: İ. al-Riyāḍ: maktabah al-Malik Fahd alWațīah, 2011

Al-Fauzān, 'Abd al-Raḥmān bin Ibrāhīm wa aṣdiqā'uh. Al- 'Arabīah baina yadaīk. AlȚab'ah: III. Al-Riyāḍ: al- 'Arabīah liljamī', 2003

Al-Hāsyimī, al-Sayyid Āḥmad. Al-Qawā id al-Asāsīah lì al-Lugah al-'Arabīah. Bīrūt: dār al-Kutub al-'Ilmiah, 1971 


\section{البصيرة: مجلة الاراسات الإسلامية \\ AL-BASHIRAH: JOURNAL OF ISLAMIC STUDIES \\ Vol. 2 No. 1 (2021): 49-65}

Website: https://journal.stiba.ac.id

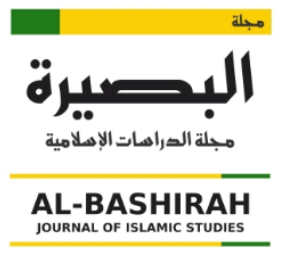

Al-Ḥāmid, 'Abdullāḥ bin Hāmid. Kitāb al-Naḥw min silsilah ta'līm al-Lugah al'Arabiah lī al-Mustawā al-s̄ānī. Al-Ṭab'ah: II. Al-Riyāḍ: jāmi'ah al-Imām Muhammad bin Sa 'ùd al-Islāmīah, 2004

Ibrāhīm, 'Abd al-'Alīm. Al-Muwajjih al-Fannī lī mudarrisī al-Lugah al-'Arabiah. AlȚab'ah: X. Al-Qāhirah: dār al-Ma'ārif, 1962

Ibnu Taīmiah, taqī al-dīn al-Harrān̄i. Iqtiḍā al-Ṣirạt al-Mustaqīm. Bīrūt: dār al- 'Ālam alKutub, 1999

'Iswai, Aḥmad Murgani. Silsilah ta 'īm al-Lugah al-'Arabīah -kitāb al-Naḥw lī alMustawā al-s̄ān̄i-. Al-Riyāḍ: jāmi 'ah Muḥammad bin Sa'ūd al-Islāmīah, 2004

Madkūr, 'Alī Aḥmad. Ṭuruq tadrīs al-Lugah al-'Arabiah. Al-Ṭab'ah: I. 'Umān: dār alMasīrah, 2006

Nāqah, Mạ̣mūd Kāmil. Ta 'Tìm al-Lugah al-'Arabiah lì al-Nātiqīna bilugāt ukhra asasuh wa madākhiluh wa turuq tadrīsih-. Al-Mamlakah al-'Arabiah alSu 'ūdiah: jāmi 'ah ummu al-Qurā wizārah al-Ta 'ālīm al- 'Ālì, 1980

Al-Simān, Maḥmūd 'Alī. Al-taujīh fì tadrīs al-Lugah al-'Arabiah. Al-Qāhirah: dār alMa'ārif, 1983

Șīn̄e, Maḥmūd Ismā̄ōl wa aṣdiqā'uh. Mursyid al-Mu'allim fì tadrīs al-Lugah al'Arabīah ligaīri al-Nāțiqina biha. Al-Ṭab'ah: II. Al-Riyāḍ: maktabah al-Tarbiah al-'Arabī lidaūl al-Khalīj 1986

Taīmūr, Maḥmūd. Musykilāt al-Lugah al- 'Arabīah. Duna al-Ṭab'ah. Bīrūt: mansyūrāṭ al-Maktabah al-'Așrīah, duna sanah

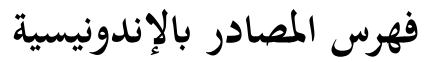

Arsyad, Azhar. Bahasa Arab dan Metode Pengajarannya. Cet. II; Jogjakarta: Pustaka Pelajar, 2004.

Mardiyah, Tika. Problematika Pengajaran Bahasa Arab Di Madrasah Tsanawiyah Pesantren Sabilil Muttaqin Tulungagung. Jurnal Prespektive, Vol.X, No. 02 (2017).

Munir, Perencanaan Sistem Pengajaran Bahasa Arab. Cet. I; Jakarta: Kencana; 2017.

Nisa, Luthfi Farihatun, Bety Istif Fani dan Arya Wahyu Pratama. Kitab Turats Sebagai Solusi Efektifitas Pembelajaran Mata Kuliah Tarkib Ibtida'i di Jurusan Sastra Arab Universitas Negeri Malang. Prosiding. Vol. 4 (2020). http://prosiding.arabum.com/index.php/semnasbama/article/view/618.

Susanti, Reni Dwi. Studi Analisis Buku Ajar “Buku Teks Pelajaran” Pada mata Pelajaran Bahasa Arab di Kelas Tinggi Madrasah Ibtidaiah. Jurnal Arabia, Vol. 5 No. 2 (April- 2013 ). https://journal.iainkudus.ac.id/index.php/Arabia/article/view/1389.

Zainuri, Muhammad. Analisis Buku Ajar Belajar Membaca Kitab Kuning Metode Ibtida'i Karya Mujahidin Rohman. Jurnal Arabia, Vol. 11, No. 1, 2019. https://journal.iainkudus.ac.id/index.php/Arabia/article/view/5255. 